University of Nebraska - Lincoln

DigitalCommons@University of Nebraska - Lincoln

1985

Evaluation of Mark-Recapture for Estimating Striped Skunk Abundance

Raymond J. Greenwood

Alan B. Sargeant

Douglas H. Johnson

USGS Northern Prairie Wildlife Research Center, Douglas_H_Johnson@usgs.gov

Follow this and additional works at: https://digitalcommons.unl.edu/usgsnpwrc

Part of the Other International and Area Studies Commons

Greenwood, Raymond J.; Sargeant, Alan B.; and Johnson, Douglas H., "Evaluation of Mark-Recapture for Estimating Striped Skunk Abundance" (1985). USGS Northern Prairie Wildlife Research Center. 217.

https://digitalcommons.unl.edu/usgsnpwrc/217

This Article is brought to you for free and open access by the US Geological Survey at DigitalCommons@University of Nebraska - Lincoln. It has been accepted for inclusion in USGS Northern Prairie Wildlife Research Center by an authorized administrator of DigitalCommons@University of Nebraska - Lincoln. 
This article is a U.S. government work, and is not subject to copyright in the United States.

\title{
EVALUATION OF MARK-RECAPTURE FOR ESTIMATING STRIPED SKUNK ABUNDANCE
}

RAYMOND J. GREENWOOD, U.S. Fish and Wildlife Service, Northern Prairie Wildlife Research Center, Jamestown, ND 58401 ALAN B. SARGEANT, U.S. Fish and Wildlife Service, Northern Prairie Wildlife Research Center, Jamestown, ND 58401 DOUGLAS H. JOHNSON, U.S. Fish and Wildlife Service, Northern Prairie Wildlife Research Center, Jamestown, ND 58401

\begin{abstract}
The mark-recapture method for estimating striped skunk (Mephitis mephitis) abundance was evaluated by systematically livetrapping a radio-equipped population on a $31.4-\mathrm{km}^{2}$ study area in North Dakota during late April of 1977 and 1978. The study population was 10 females and 13 males in 1977 and 20 females and 8 males in 1978. Skunks were almost exclusively nocturnal. Males traveled greater nightly distances than females ( 3.3 vs. $2.6 \mathrm{~km}, P<0.05$ ) and had larger home ranges (308 vs. $242 \mathrm{ha}$ ) although not significantly so. Increased windchill reduced night-time activity. The population was demographically but not geographically closed. Frequency of capture was positively correlated with time skunks spent on the study area. Little variation in capture probabilities was found among trap-nights. Skunks exhibited neither trap-proneness nor shyness. Capture rates in 1977 were higher for males than for females; the reverse occurred in 1978. Variation in individual capture rates was indicated among males in 1977 and among females in 1978. Ten estimators produced generally similar results, but all underestimated true population size. Underestimation was a function of the number of untrapped skunks, primarily those that spent limited time on the study area. The jackknife method produced the best estimates of skunk abundance.
\end{abstract}

J. WILDL. MANACE. 49(2):332-340

The estimation of animal abundance is often difficult. Mark-recapture is used commonly to estimate the abundance of secretive mammals, including striped skunks (Verts 1967, Bailey 1971, Lynch 1972). Although there are many estimators available (Cormack 1968, 1979; Otis et al. 1978; Pollock 1981; Seber 1982), there are few data on their application to populations of known size. This paper assesses the applicability of several estimators with data for populations of striped skunks of known size in 2 years and discusses aspects of skunk biology that influence capture probability. Although captures in this study are fewer than desired for most markrecapture evaluations, the approach represents a practical application of the mark-recapture method.

W. B. Bicknell and J. L. Piehl provided field assistance. Radiotelemetry equipment was obtained from the James Ford Bell Mus., Cedar Creek Natl. Hist. Area, Univ. of Minnesota, St. Paul. D. R. Anderson and G. C. White provided the CAPTURE computer program. Appreciation is extended to D. W. Sparling, who verified 
some of the calculations and reviewed the manuscript, and to D. R. Anderson, K. P. Burnham, R. M. Cormack, L. L. Eberhardt, D. L. Otis, K. H. Pollock, and G. C. White, who provided constructive comments on the manuscript.

\section{STUDY AREA AND METHODS}

The study was conducted in 1977 and 1978 on a $31.4-\mathrm{km}^{2}$ area near Walum in southern Griggs County, North Dakota. The gently rolling landscape was a mosaic of large grain fields interspersed with marshes, farmsteads, tree plantings, and pastures; $80 \%$ of the land was cultivated. Climate is continental with cold winters and warm summers. Snowmelt occurs in late March and early April.

The study area was partitioned into a $7 \times 7$ grid of square $0.65-\mathrm{km}^{2}$ plots. Livetrapping for striped skunks was conducted during 3-9 April 1977 and 4-10 April 1978 to radio-equip study animals. Two or three single-door, wire-mesh traps $(25 \times 30 \times 81 \mathrm{~cm})$ were baited with canned sardines and set at favorable sites in each plot. Traps were checked each morning. Captured animals were anesthesized with ketamine $\mathrm{HCl}$ (Beck 1976) and equipped with a radio collar; weight, sex, and general physical condition were recorded. The known-size study population each year comprised all skunks captured during early April that were alive at the end of the mark-recapture evaluation period and radio-tracked on the study area at least once during the April evaluation period.

To facilitate this evaluation, eight trap sites were selected per plot in 1977 and four in 1978. Most sites were near field edges, trails, rock piles, and abandoned buildings. No site was within $100 \mathrm{~m}$ of another. Trapping was conducted on eight alternate nights between 16 April and 1 May in 1977, and on four alternate nights between 23 and 30 April in 1978. Traps were placed at one site chosen randomly from those in each plot. Each site was used only once. Traps were set in the afternoon and removed the next morning. Fresh bait was used each day. Radioed skunks were released immediately, whereas new skunks (not included in mark-recapture study populations) were radio-equipped and then released.

During the evaluation period each year, the daytime retreats of all radioed skunks were located daily, and all skunks were systematically monitored during five evenly distributed track- ing periods lasting 24 hours in 1977 and 14 hours (all night) in 1978. Each skunk was located at approximately 2-hour intervals during monitoring. Trapping and tracking were conducted on different nights; telemetry locations for trapped skunks were not recorded until 1012 hours after the trapped animal had been released from the trap. Activity stage (moving or resting) was determined from radio-signal characteristics each time a skunk was located. Data from the study population and from skunks first caught during the evaluation were used to analyze movements and behavior. The summation of straight-line distances between consecutive locations was used as an index to distance traveled by skunks for which complete records were available per 14- or 24-hour tracking period. Home-range sizes were estimated by the minimum-area method (Mohr 1947) for skunks located during every tracking period. Precipitation amounts and temperature extremes were recorded daily. Wind velocity and time of precipitation were estimated periodically during each tracking period.

\section{POPULATION CHARACTERISTICS}

Twenty-four skunks were captured and radio-equipped prior to the evaluation period in 1977 and 34 in 1978. The study populations, excluding nonvisitors to the study area ( $1 \mathrm{fe}$ male, 3 males) and deaths ( 1 female, 2 males), were 10 females and 13 males in 1977 and 20 females and 8 males in 1978 (Table 1); 5 individual females were present in both years. Totals of 588 trap-nights and 133 skunk captures ( 0.23 captures/trap-night) were recorded during the mark-recapture evaluation period in the 2 years. New skunks captured during the evaluation periods totaled 23 in 1977 and 4 in 1978.

\section{Diel Activity Patterns}

Skunk movements occurred principally during night-time. Movement increased just before sunset, reached peak levels within 1-2 hours thereafter, and then gradually declined until sunrise, at which time most skunks became inactive. Temporal activity patterns of males and females were similar. Daytime movement typically occurred near rest sites.

Windchill negatively affected skunk movements. The night of 19-20 April 1978 was the coldest on which tracking was conducted; the minimum temperature was $-6 \mathrm{C}$ and the maximum windchill was $-24 \mathrm{C}$. Between 1800 and 
Table 1. Number of striped skunks in a North Dakota study population exhibiting particular capture histories during markrecapture evaluation period in April 1977 and 1978. For instance, the first line indicates that one female and three males in 1977 and seven females and four males in 1978 were not captured during the evaluation period, and the last line indicates that one male in 1977 was captured on occasions 2, 3, 5,7 , and 8 .

\begin{tabular}{|c|c|c|c|c|}
\hline \multirow[b]{2}{*}{ Capture history } & \multicolumn{2}{|c|}{1977 (8 trap-nights) } & \multicolumn{2}{|c|}{1978 (4 trap-nights) } \\
\hline & $\begin{array}{c}N \\
\text { females }\end{array}$ & $\begin{array}{c}N \\
\text { males }\end{array}$ & $\begin{array}{c}N \\
\text { females }\end{array}$ & $\begin{array}{c}N \\
\text { males }\end{array}$ \\
\hline Not captured & 1 & 3 & 7 & 4 \\
\hline 1 & 1 & & 3 & 2 \\
\hline 2 & 1 & & 2 & \\
\hline 3 & & & 2 & \\
\hline 4 & & & & 1 \\
\hline $1-2$ & & & 1 & \\
\hline $1-3$ & & & & 1 \\
\hline $1-7$ & 1 & & & \\
\hline $2-3$ & 2 & & 1 & \\
\hline $2-4$ & & & 1 & \\
\hline $3-6$ & & 2 & & \\
\hline 3-7 & & 1 & & \\
\hline $5-8$ & 1 & & & \\
\hline $1-2-4$ & & & 1 & \\
\hline $1-4-6$ & & 1 & & \\
\hline $1-6-8$ & & 1 & & \\
\hline $2-3-4$ & & 1 & & \\
\hline $4-5-6$ & 1 & & & \\
\hline $4-6-8$ & 1 & & & \\
\hline $1-2-3-4$ & & & 2 & \\
\hline $2-4-5-7$ & & 1 & & \\
\hline $3-6-7-8$ & 1 & & & \\
\hline $4-6-7-8$ & & 1 & & \\
\hline $1-3-5-7-8$ & & 1 & & \\
\hline $2-3-5-7-8$ & & 1 & & \\
\hline
\end{tabular}

0600 hours that night, skunks were actively traveling $25 \%$ of the time as compared with $74 \%$ on other nights.

\section{Nightly Travel Distances}

Indices of distances traveled nightly by skunks ranged from 0.0 to $9.3 \mathrm{~km}$ for 26 females $(N=$ 79 skunk-nights) and from 0.4 to $10.5 \mathrm{~km}$ for 19 males $(N=47)$. All skunks traveled extensively each night, except 19-20 April 1978 when $9(41 \%)$ of 22 travel distances were $<1 \mathrm{~km}$ compared with $4(4 \%)$ of 104 instances on the other nights. Female travel indices averaged $2.7 \pm$ $1.6(\mathrm{SD})$ and $2.6 \pm 1.6 \mathrm{~km}$, and those of males $3.3 \pm 2.1$ and $3.3 \pm 1.6 \mathrm{~km} /$ night in 1977 and 1978 , respectively. There were differences between sexes for years combined $(F=6.27,1$ and $76 \mathrm{df}, P<0.05)$. Travel was correlated with windchill $(r=0.806, P<0.01)$, mostly because of reduced movement during the night of 1920 April 1978. There was no difference in dis- tances traveled among individuals within sex $(F=0.92,39$ and $76 \mathrm{df}, P>0.10)$.

\section{Home-Range Size}

Home ranges of 24 females averaged $242 \pm$ $119 \mathrm{ha}$ ( 87 to $543 \mathrm{ha}$ ), whereas those of 15 males averaged $308 \pm 170$ ha (98 to 688 ha). Numbers of locations per skunk averaged 30 (range 22$35)$. Neither year $(P=0.63)$ nor sex $(P=0.15)$ was related to range size. Although these data were inadequate to define range size, they showed that each skunk used an area that encompassed several trap sites.

\section{Time Spent on Study Area}

The amount of time each skunk spent on the study area depended largely on size and location of its home range with respect to the study area. In 1977 and 1978, six (26\%) and four (14\%) of the monitored skunks remained exclusively on the study area. Frequency of capture was positively correlated with amount of time spent on the study area $(r=0.47, \mathrm{df}=49, P<0.001)$. However, one male skunk not captured during the 1977 evaluation period was on the study area $93 \%$ of the times he was located, and two females not captured during the 1978 period were on the study area 80 and $88 \%$ of the times located.

\section{VALIDITY OF ASSUMPTIONS}

Estimators developed for use with capture data incorporate certain basic assumptions enumerated by Otis et al. (1978) and Seber (1982). Important assumptions are that the population is demographically closed-no animals are born, die, or migrate into or out of the area during the trapping period-and that markers are retained. Another common assumption, that all animals have constant and equal probability of capture, is generally difficult to satisfy. Otis et al. (1978) discussed a sequence of models that relax the latter assumptions by allowing capture probability to vary with (1) trapping occasion; (2) behavioral response after capture; and (3) heterogeneity among animals, including differences between sexes. These three assumptions were evaluated in the present study.

\section{Closure}

Emigration and immigration had negligible impact on study populations; only one male skunk was suspected of dispersing from the study area (in 1977). Certain "edge" animals 
Table 2. Expected and observed number of captures, based on 16 female and 4 male striped skunks with more than $80 \%$ of telemetry locations within a North Dakota study area during evaluation periods in 1977 and 1978.

\begin{tabular}{lllllll}
\hline & \multicolumn{7}{c}{$N$ captures } \\
\cline { 2 - 7 } & \multicolumn{1}{c}{0} & \multicolumn{1}{c}{1} & \multicolumn{1}{c}{2} & \multicolumn{1}{c}{3} & \multicolumn{1}{c}{4} & $5+$ \\
\hline Expected & 1.42 & 4.76 & 6.77 & 4.92 & 1.77 & 0.36 \\
Observed & 2 & 3 & 8 & 5 & 2 & 0 \\
\hline
\end{tabular}

moved in and out of the study areas; hence, the populations were closed demographically but not geographically (White et al. 1982). No births occurred, and the deaths of three skunks did not influence study results because these skunks were not included in the study population.

\section{Retention of Markers}

All radio collars used in this study were retained and functioned properly throughout the evaluation period. Hence, the potential source of bias caused by marker loss was not present.

\section{Capture Probability}

Variation by Trapping Occasion.-Differences in capture probabilities among trapping occasions were sought by comparing numbers of captures per night. Captures per night were not different in 1977 (range $=5-9, \chi^{2}=2.94$, $\mathrm{df}=7, P>0.5)$ or 1978 (range $=5-10, \chi^{2}=$ $2.75, \mathrm{df}=3, P=0.43$ ). Thus, study animals did not exhibit differential susceptibility to trapping on different nights.

Behavioral Response to Capture.-The distribution of number of captures of 16 females and 4 males with more than $80 \%$ of their radiolocations within the study area was examined to evaluate behavioral responses to traps. Because all animals had been caught previously, trap-happiness would have been indicated if many animals had been captured many times and, conversely, trap-shyness would have been indicated if many animals had not been captured during the evaluation period. The close fit of expected and observed capture frequen$\operatorname{cies}\left(\chi^{2}=1.50, \mathrm{df}=5, P>0.25\right)$ suggested that neither trap-happiness nor trap-shyness appreciably affected capture rate (Table 2 ).

Heterogeneity.-In contrast to females, males moved farther at night and tended to have larger ranges. Hence, males conceivably could have had higher probabilities of capture than females. However, in neither year did capture rate differ between sexes; the capture rates were
0.317 for males and 0.250 for females in 1977 $\left(\chi^{2}=0.70, \mathrm{df}=1, P>0.5\right)$ and 0.156 for males and 0.300 for females in $1978\left(\chi^{2}=1.77, \mathrm{df}=\right.$ $1, P=0.18$ ).

Heterogeneity in catchability was evaluated by considering the distribution of frequency of capture among individuals (Leslie 1958). Variation in catchability could be either consistent with binomial events or a reflection of heterogeneity within the study population. If, for example, the eight trapping occasions in 1977 represented eight replications of a binomial event for each of the males trapped, and the probability of "success" (capture) was 0.317 , the expected variance would have been $8(0.317)$. $(1-0.317)=1.73$. The actual variance of the distribution of captures was 3.10. Variation in captures of males was greater than expected for a homogeneous binomial population in 1977 $(P=0.044)($ Table 3$)$ and could have resulted from variation in trapping occasion or heterogeneity among subpopulations. A further test (Leslie 1958), which eliminates any effect of variation among trapping occasions, gave an expected variance of 1.68 , which was less than the observed variance of $3.10(P=0.036)$. Results of the two tests were similar within each group (Table 3). The 1977 females and 1978 males appeared homogeneous with respect to capture probability. The 1977 males and 1978 females appeared heterogeneous, each group containing an excessive number of animals captured zero times. Radiotelemetry data showed that most of these animals had relatively small portions of their home ranges in the study area.

\section{APPLICATION OF MARK-RECAPTURE MODELS AND COMPARISON OF ESTIMATORS}

Among the estimators evaluated with respect to these skunk populations of known size are those recommended by Otis et al. (1978) for different situations, depending upon the extent of variation with trapping occasion, behavioral changes in catchability following initial capture, and heterogeneity among animals.

The accuracy of the estimates was summarized by considering the relative error, computed as the difference between an estimate and the true value, ignoring sign, divided by the true value. These were averaged across the six subpopulations to produce the average relative error (ARE) (Table 4). For those estimators with standard errors, the difference be- 
Table 3. Comparison of observed variance of skunk capture distribution to that expected under homogeneous binomial models with equal (e) or possibly unequal $(u)$ capture rates among occasions.

\begin{tabular}{|c|c|c|c|c|c|c|}
\hline \multirow{2}{*}{$\begin{array}{c}\text { Subpopu- } \\
\text { lation }\end{array}$} & \multirow[b]{2}{*}{ Capture rate } & \multicolumn{3}{|c|}{ Variance } & \multirow[b]{2}{*}{ Prob $_{e}$} & \multirow[b]{2}{*}{$\operatorname{Prob}_{u}$} \\
\hline & & Observed & Expected (e) & Expected (u) & & \\
\hline \multicolumn{7}{|l|}{1977} \\
\hline Females & 0.2500 & 1.3333 & 1.5000 & 1.4800 & 0.533 & 0.517 \\
\hline Males & 0.3173 & 3.1026 & 1.7330 & 1.6805 & 0.044 & 0.036 \\
\hline Both & 0.2880 & 2.3123 & 1.6404 & 1.6143 & 0.097 & 0.086 \\
\hline \multicolumn{7}{|l|}{1978} \\
\hline Females & 0.3000 & 1.6421 & 0.8400 & 0.8150 & 0.008 & 0.005 \\
\hline Males & 0.1562 & 0.5536 & 0.5273 & 0.4531 & 0.394 & 0.286 \\
\hline Both & 0.2589 & 1.3690 & 0.7675 & 0.7487 & 0.007 & 0.005 \\
\hline
\end{tabular}

tween estimate and true value, sign again ignored, divided by the estimated standard error, was calculated. The median of these values, termed the median standardized difference (MSD) (Table 4), incorporated both bias of the estimator and inaccuracy of its standard error. A large MSD indicated that estimates were several standard errors away from the true value; hence, confidence intervals developed from such estimates were unlikely to contain the true value.

Model with No Variation (Null).-The simplest but most restrictive model assumes that the probability of capturing an animal is the same for all animals and on each trapping occasion. Darroch (1958) discussed this model and

Table 4. Comparison of known-size North Dakota skunk subpopulations (in parentheses) with values estimated by several mark-recapture models ( \pm standard errors), average relative errors, and medlan standardized differences for the estimators.

\begin{tabular}{|c|c|c|c|c|c|c|c|c|}
\hline \multirow{2}{*}{$\begin{array}{l}\text { Types of heteroge- } \\
\text { neity permitted by } \\
\text { models and estimators }\end{array}$} & \multicolumn{3}{|c|}{1977} & \multicolumn{3}{|c|}{1978} & \multirow{2}{*}{$\begin{array}{l}\text { Aver- } \\
\text { age } \\
\text { rela- } \\
\text { tive } \\
\text { error }\end{array}$} & \multirow{2}{*}{$\begin{array}{c}\text { Median } \\
\text { stan- } \\
\text { dardized } \\
\text { dif- } \\
\text { ference }\end{array}$} \\
\hline & $\begin{array}{c}\text { Females } \\
(10)\end{array}$ & $\begin{array}{c}\text { Males } \\
(13)\end{array}$ & $\begin{array}{l}\text { Both } \\
\text { (23) }\end{array}$ & $\begin{array}{c}\text { Females } \\
(20)\end{array}$ & $\underset{(8)}{\text { Males }}$ & $\begin{array}{l}\text { Both } \\
(28)\end{array}$ & & \\
\hline \multicolumn{9}{|l|}{ None (null) } \\
\hline $\begin{array}{l}\text { Maximum likeli- } \\
\text { hood }\end{array}$ & $\begin{array}{r}9.23 \\
\pm 1.04\end{array}$ & $\begin{array}{r}10.00 \\
\pm 0.40\end{array}$ & $\begin{array}{r}19.09 \\
\pm 0.87\end{array}$ & $\begin{array}{r}14.04 \\
\pm 1.62\end{array}$ & $\begin{array}{r}6.27 \\
\pm 3.78\end{array}$ & $\begin{array}{r}19.72 \\
\pm 2.59\end{array}$ & 0.21 & 3.44 \\
\hline \multicolumn{9}{|l|}{ Trapping occasion } \\
\hline $\begin{array}{l}\text { Maximum likeli- } \\
\text { hood }\end{array}$ & $\begin{array}{r}9.00 \\
\pm 0.47\end{array}$ & $\begin{array}{r}10.00 \\
\pm 0.01\end{array}$ & $\begin{array}{r}19.00 \\
\pm 0.24\end{array}$ & $\begin{array}{r}14.00 \\
\pm 1.05\end{array}$ & $\begin{array}{r}4.00 \\
\pm 0.01\end{array}$ & $\begin{array}{r}19.00 \\
\pm 2.06\end{array}$ & 0.27 & 11.19 \\
\hline Schnabel & $\begin{array}{r}11.00 \\
\pm 3.65\end{array}$ & $\begin{array}{r}10.91 \\
\pm 2.39\end{array}$ & $\begin{array}{r}21.38 \\
\pm 3.79\end{array}$ & $\begin{array}{r}14.82 \\
\pm 4.92\end{array}$ & $\begin{array}{r}6.00 \\
\pm 29.13\end{array}$ & $\begin{array}{r}20.33 \\
\pm 6.40\end{array}$ & 0.19 & 0.65 \\
\hline $\begin{array}{l}\text { Mean Lincoln- } \\
\text { Petersen }\end{array}$ & $\begin{array}{r}11.07 \\
\pm 1.63\end{array}$ & $\begin{array}{r}11.11 \\
\pm 0.69\end{array}$ & $\begin{array}{r}23.69 \\
\pm 3.09\end{array}$ & $\begin{array}{r}14.47 \\
\pm 1.27\end{array}$ & $\begin{array}{r}4.33 \\
\pm 1.33\end{array}$ & $\begin{array}{r}19.40 \\
\pm 0.35\end{array}$ & 0.22 & 2.75 \\
\hline $\begin{array}{l}\text { Schumacher- } \\
\text { Eschmeyer }\end{array}$ & $\begin{array}{r}10.39 \\
\pm 2.20\end{array}$ & $\begin{array}{r}10.54 \\
\pm 0.71\end{array}$ & $\begin{array}{r}20.59 \\
\pm 1.80\end{array}$ & $\begin{array}{r}14.80 \\
\pm 4.19\end{array}$ & $\begin{array}{r}6.00 \\
\pm 2.26^{*}\end{array}$ & $\begin{array}{r}20.35 \\
\pm 0.72\end{array}$ & 0.19 & 1.29 \\
\hline Tanaka & 11.05 & 10.18 & 20.39 & 15.13 & & 20.59 & 0.19 & \\
\hline \multicolumn{9}{|l|}{ Behavioral response } \\
\hline Zippin & $\begin{array}{r}9.00 \\
\pm 0.58\end{array}$ & $\begin{array}{r}10.00 \\
\pm 0.31\end{array}$ & $\begin{array}{r}19.00 \\
\pm 0.61\end{array}$ & $\begin{array}{r}13.00 \\
\pm 0.66\end{array}$ & $\begin{array}{r}4.00 \\
\pm 0.50\end{array}$ & $\begin{array}{r}17.00 \\
\pm 0.81\end{array}$ & 0.29 & 8.84 \\
\hline \multicolumn{9}{|l|}{ General } \\
\hline Jackknife & $\begin{array}{r}10.75 \\
\pm 1.81\end{array}$ & $\begin{array}{r}10.00 \\
\pm 0.00\end{array}$ & $\begin{array}{r}20.75 \\
\pm 1.81\end{array}$ & $\begin{array}{r}18.25 \\
\pm 3.03\end{array}$ & $\begin{array}{r}6.25 \\
\pm 1.98\end{array}$ & $\begin{array}{r}24.50 \\
\pm 3.62\end{array}$ & 0.14 & 0.93 \\
\hline Overton & $\begin{array}{r}10.54 \\
\pm 1.46\end{array}$ & $\begin{array}{r}10.41 \\
\pm 0.67\end{array}$ & $\begin{array}{r}20.96 \\
\pm 1.61\end{array}$ & $\begin{array}{r}16.44 \\
\pm 2.23\end{array}$ & $\begin{array}{r}5.46 \\
\pm 1.45\end{array}$ & $\begin{array}{r}21.90 \\
\pm 2.66\end{array}$ & 0.18 & 1.67 \\
\hline Geometric & $\begin{array}{r}15.55 \\
\pm 4.69\end{array}$ & $\begin{array}{r}13.91 \\
\pm 2.90\end{array}$ & $\begin{array}{r}29.06 \\
\pm 4.98\end{array}$ & $\begin{array}{r}27.18 \\
\pm 8.20\end{array}$ & $\begin{array}{r}16.00 \\
\pm 16.00\end{array}$ & $\begin{array}{r}39.67 \\
\pm 11.45\end{array}$ & 0.44 & 0.95 \\
\hline
\end{tabular}

a Upper $95 \%$ confidence limit for 1978 males was infinite; standard error was taken to be $1 / 2$ of the difference between subpopulation estimate and lower confidence limit. 
developed the maximum likelihood (ML) estimator and its variance. The program CAPTURE of White et al. (1978) calculates the relevant quantities.

Analyses indicated the presence of little or no variation due to trapping occasion, behavioral changes, or heterogeneity. The estimators for the model with no variation performed fairly well (Table 4). The assumptions of the null model are difficult to satisfy in general; consequently, the ML estimator corresponding to this model is not recommended. Its ARE was fairly large, 0.21 , and its MSD of 3.44 suggested that estimated standard errors were too small and would give false feelings of adequacy about estimates. The estimator is not robust to violation of the assumptions of the null model (Otis et al. 1978).

Model Allowing Variation in Trapping Occasion.-Darroch (1958) developed ML estimators for this model, which are also included in program CAPTURE (White et al. 1978). The Lincoln-Petersen estimator is applicable here for two trapping occasions and can be generalized; the Schnabel estimator was developed for more than two occasions. Several regression estimators also have been suggested for this situation.

These estimators seemingly would offer little improvement over the null model because there was no variation due to trapping occasions in 1977 and little in 1978. The ML estimates for 1977 were nearly identical to those of the null model, although the standard deviation for the males was deceptively small (Table 4). For 1978, ML estimators were worse than those of the null model.

The ML estimator performed the worst of the five estimators that accommodate variation in capture probabilities by occasion. It consistently produced underestimates of the population size and standard errors so small that none of the six $95 \%$ confidence intervals contained the true population values. Otis et al. (1978) suggested that this method would yield useful values if average capture probabilities exceeded $0.20-0.30$, a condition met in this population of skunks, but warned that heterogeneity would produce a negative bias.

The Schnabel (1938) estimator, with standard errors $1 / 4$ of the length of the $95 \%$ confidence interval (Overton 1969:table 21.1), performed better than the ML estimator for the same situation. Estimates were close to true val- ues for all subpopulations. Moreover, standard errors for the Schnabel method more closely portrayed the true inaccuracy than did those of the ML estimator.

The Lincoln-Petersen estimator was calculated for all but the first occasion by considering the marked population to be the animals marked on any previous occasion. The average of the resulting estimates is the mean Lincoln-Petersen estimate (Seber 1982), and its standard error can be estimated from the sample variance of the individual estimates. Mean Lincoln-Petersen estimates tended to be more biased than Schnabel, particularly for the 1978 males. Standard errors were deceptively small as well. Seber (1982) opined that this estimator might be more robust than others of the Schnabel form, and Cormack (1968) indicated it to be less sensitive to unequal capture rates. Sefcik (1980) found Lincoln-Petersen (with an averaging method different from the one used for this data set) and Schnabel methods both underestimated sizes of his trap-happy animals. Mares et al. (1981), who applied several mark-recapture estimators to a known population of eastern chipmunks (Tamias striatus), found that the Lincoln-Petersen estimates were somewhat more accurate than Schnabel and SchumacherEschmeyer, although all were biased low. Standard errors for chipmunks were larger for the Lincoln-Petersen estimator, whereas those for the other estimators often yielded confidence limits that did not include the true value.

The regression method of Schumacher and Eschmeyer, with standard errors $1 / 4$ of the length of the 95\% confidence interval (Seber 1982: equation 4.17), performed about as well as Schnabel's, although estimated standard errors were optimistically small. Sefcik (1980) and Seber (1982) indicated that the Schmacher-Eschmeyer method was more robust but less efficient than Schnabel.

The regression method of Tanaka (Seber 1982) was used for five of six of our groups (Table 4); the 1978 males had too few occasions with recaptures to perform the regression. Tanaka's estimator was similar to SchmacherEschmeyer; standard error estimates were not conveniently available. Carothers (1973) found that Tanaka's method produced little gain over estimators assuming equal catchability, and standard errors were large. Sefcik (1980) obtained highly variable results from Tanaka's method-biases were sometimes positive, 
sometimes negative, and the estimator often could not be calculated.

Model with Behavioral Response.-Under the conditions appropriate for this model, capture probability changes after the initial capture. This situation was inappropriate for our study populations because all skunks had been caught before the evaluation. Nonetheless, the presence of behavioral changes would be of general interest; earlier tests for trap response showed none.

The estimator recommended by Otis et al. (1978) for this model is equivalent to the removal method of Zippin (1956, 1958). The estimator equaled the total number of different skunks captured during the evaluation period for all six subpopulations (Table 4). Standard errors are from Zippin (1956), as calculated by the CAPTURE program of White et al. (1978).

This estimator performed poorly, being strongly negative biased and yielding standard errors optimistically small. Otis et al. (1978) recommended its use when animals alter their behavior after initial capture, a circumstance not encountered in this study. They also noted a negative bias in the presence of general heterogeneity.

Model with General Heterogeneity.-This model permits animals within a population to have individual but constant probabilities of capture that do not change after initial capture. Burnham (1972) and Burnham and Overton (1978) developed nonparametric "jackknife" estimators appropriate for this model based on the frequency of capture distribution. Jackknife estimators of several orders can be calculated; bias generally decreases but variance increases with higher-order estimators. The first-order estimator was used because of its simplicity and low variance.

Previous analyses indicated that some subpopulations exhibited heterogeneity, suggesting that the jackknife estimator would perform well for these groups. The estimate for males in 1977 was no better than most other estimators, but that for the females in 1978 was the closest obtained to the actual number. The 1977 female population was overestimated slightly, whereas the 1978 male population was underestimated.

The jackknife estimator, recommended by Otis et al. (1978) for heterogeneous populations, gave the best results of all methods tested. Its ARE was 0.14 , and its standard errors were useful, except for the zero value recorded for males in 1977. Ninety-five percent confidence intervals for the other five groups easily contained the true value. Otis et al. (1978) found the method to have a small bias if the number of trapping occasions exceeded five and if there were few "untrappable" animals.

Overton's (1969) nonparametric estimator based on frequency of occurrence data was calculated with standard error estimates from Burnham and Overton (1978:equation 6). It performed nearly as well as the jackknife estimator (Table 4); its ARE was 0.18, and its standard errors were appropriate. Zarnoch (1976) claimed this estimator to be the best, among five he examined, when capture probabilities vary. Sefcik (1980) found the bias of this estimator to decrease with the number of trapping occasions.

The geometric model, a parametric method generally more applicable than the other parametric methods (Eberhardt 1969), was also evaluated. The geometric consistently overestimated the population size, often severely ( $\mathrm{Ta}$ ble 4). Estimated standard errors, calculated by a formula provided by K. P. Burnham (pers. commun.) were taken as the population estimate divided by the square root of (total captures minus the number of individuals captured). Standard errors tended to be large, especially for the 1978 groups. Results of the geometric estimator were virtually useless; its ARE was 0.44 and it consistently overestimated true population sizes, a feature also noted by Sefcik (1980). Carothers (1973) indicated that the geometric estimator was positively biased when catchability was equal, but the bias declined when heterogeneity increased. Support for the latter contention was weak; the correlation coefficient between the relative error of the geometric estimator and $\mathrm{Prob}_{e}$, a measure of heterogeneity (Table 3 ), was $r=0.680$, which was not significant $(P=0.15, \mathrm{df}=4)$.

\section{DISCUSSION}

Late April appeared to be the best time for using mark-recapture to estimate striped skunk abundance in North Dakota because the animals were both responsive to bait and traveled widely, and the population was demographically stable. Furthermore, habitat conditions are bleak in April, which enhanced selection of favorable trap sites. Problems with closure would arise after April because of recruitment and dis- 
persal (Verts 1967, Bjorge et al. 1981, Sargeant et al. 1982).

The daily shift of traps was time-consuming but eliminated possible problems associated with individual skunks becoming habituated to sites and probably increased total exposure to capture. Capture was further enhanced by setting traps at sites where disturbance was minimal. Cold weather, which reduced skunk movements, was the only potentially serious negative aspect to using mark-recapture during late April. That problem could be avoided largely by using data only from nights when acceptable weather conditions prevailed or by using an estimator that allows variation among trapping occasions.

Nearly all of our estimates of population size were low. This bias apparently reflected low probability of capture for certain skunks, particularly those that had most of their home range outside the study area. Increased probability of capture could have been achieved by using a greater density of traps, more trapping occasions, or a larger study area.

In spite of considerable effort, sampling procedures used in this study barely met the criteria of Otis et al. (1978), who suggested use of about four traps per home range; our placement averaged 4.8. Capture probabilities averaged 0.29 in 1977 and 0.24 in 1978 , which were somewhat less than the minimum of 0.30 suggested for limited trapping occasions and populations $<100$ (White et al. 1982). Although the recommended grid-trapping system was used, the $7 \times 7$ grid that encompassed $31.4 \mathrm{~km}^{2}$ was much smaller than the suggested $13 \times 13$ grid minimum, which would have tripled the number of traps and size of study area. A minimal trapping period of eight to nine occasions was recommended; in this study, eight occasions were trapped in 1977 and four in 1978. In most carnivore studies where estimating population size is only one of many objectives, the cost and effort required to meet the proposed standards are often prohibitive and probably would not guarantee satisfactory estimates with the estimators available.

Considerable emphasis has been given to developing estimators that accommodate variation inherent in mark-recapture data. Investigators, however, often are not able to appreciate the nature and extent of the variation and find it difficult to select the most appropriate model. The model allowing for heterogeneity was the most appropriate for these data on skunks, and the jackknife estimator (Burnham 1972) provided the most realistic estimates of population size. However, other estimators also performed reasonably well in spite of their apparently limited suitability to our data sets.

Mark-recapture is often the only method available for estimating population size of many species of mammals. Faced with the choice of using mark-recapture or not estimating population size, investigators are often tempted to use it even though results may be of questionable quality due to poor accuracy or low precision. This situation is particularly true for carnivores that generally occur in low densities and tend to be trap-shy. For the striped skunk, however, reasonable population estimates may be obtained if investigators design a sampling scheme carefully and expend the effort necessary to obtain the needed data. Unless the population is geographically closed, a condition seldom occurring in wildlife investigations, results refer to numbers of animals using an area and not to population density, a distinction that can be easily overlooked.

\section{LITERATURE CITED}

BAILEY, T. N. 1971. Biology of striped skunks on a southwestern Lake Erie marsh. Am. Midl. Nat. 85:196-207.

BECK, C. C. 1976. VETALAR ${ }^{\circledR}$ (ketamine hydrochloride) a unique cataleptoid anesthetic agent for multispecies usage. J. Zoo Anim. Med. 7(3): 11-38.

Bjorge, R. R., J. R. Gunson, and W. M. SAMuel. 1981. Population characteristics and movements of striped skunks (Mephitis mephitis) in central Alberta. Can. Field-Nat. 95:149-155.

BuRnhAM, K. P. 1972. Estimation of population size in multiple capture-recapture studies when capture probabilities vary among animals. Ph.D. Thesis, Oregon State Univ., Corvallis. 168pp.

- , AND W. S. OVERTON. 1978. Estimation of the size of a closed population when capture probabilities vary among animals. Biometrika 65 : 625-633.

Carothers, A. D. 1973. Capture-recapture methods applied to a population with known parameters. J. Anim. Ecol. 42:125-146.

CoRMACK, R. M. 1968. The statistics of capturerecapture methods. Oceanogr. Mar. Biol. Annu. Rev. 6:455-506.

- 1979. Models for capture-recapture. Pages 217-255 in R. M. Cormack, G. P. Patil, and D. S. Robson, eds. Sampling biological populations. Int. Coop. Publ. House, Fairland, Md.

Darroch, J. N. 1958. The multiple-recapture census. I. Estimation of a closed population. Biometrika 45:343-359. 
Eberhardt, L. L. 1969. Population estimates from recapture frequencies. J. Wildl. Manage. 33:2839.

LeSLIE, P. H. 1958. Statistical appendix. J. Anim. Ecol. 27:84-86.

LYNCH, G. M. 1972. Effect of strychnine control on nest predators of dabbling ducks. J. Wildl. Manage. 36:436-440.

Mares, M. A., K. E. Streilein, and M. R. Willig. 1981. Experimental assessment of several population estimation techniques on an introduced population of eastern chipmunks. J. Mammal. 62:315-328.

MoHR, C. O. 1947. Table of equivalent populations of North American small mammals. Am. Midl. Nat. 37:223-249.

Otis, D. L., K. P. Burnham, G. C. White, and D. R. ANDERSON. 1978. Statistical inference from capture data on closed animal populations. Wildl. Monogr. 62. 135pp.

Overton, W. S. 1969. Estimating the numbers of animals in wildlife populations. Pages 403-455 in R. H. Giles, Jr., ed. Wildlife management techniques. The Wildl. Soc., Washington, D.C.

POLLOCK, K. H. 1981. Capture-recapture models: a review of current methods, assumptions, and experimental design. Pages 426-435 in C. J. Ralph and J. M. Scott, eds. Estimating numbers of terrestrial birds. Stud. Avian Biol. 6 .

Sargeant, A. B., R. J. Greenwood, J. L. Piehl, AND W. B. BICKNELL. 1982. Recurrence, mortality, and dispersal of prairie striped skunks, Mephitis mephitis, and implications to rabies epizootiology. Can. Field-Nat. 96:312-316.
SCHNABEL, Z. E. 1938. The estimation of the total fish population of a lake. Am. Math. Monthly 45:348-352.

SEBER, G. A. F. 1982. The estimation of animal abundance and related parameters. 2nd ed. Macmillan Publ. Co., New York, N.Y. 654pp.

SEFCIK, J. F. 1980. An evaluation of mark-recapture estimators utilizing field and computer techniques on known populations. M.S. Thesis, Michigan State Univ., E. Lansing. 90pp.

VERTS, B. J. 1967. The biology of the striped skunk. Univ. Illinois Press, Urbana. 218pp.

White, G. C., D. R. Anderson, K. P. Burnham, AND D. L. OTIS. 1982. Capture-recapture and removal methods for sampling closed populations. Los Alamos Natl. Lab. Publ. LA-8787NERP. 235pp.

, K. P. Burnham, D. L. Otis, and D. R. ANDERSON. 1978. User's manual for program capture. Utah State Univ. Press, Logan. 40pp.

ZARNOCH, S. J. 1976. Evaluation of estimators of population size based on simulation techniques. Ph.D. Thesis, Virginia Polytechnic Inst. and State Univ., Blacksburg. 19lpp.

ZIPPIN, C. 1956. An evaluation of the removal method of estimating animal populations. Biometrics 12:163-189.

1958. The removal method of population estimation. J. Wildl. Manage. 22:82-90.

Received 6 June 1983.

Accepted 19 September 1984. 